\title{
Non Acceptable Side Effect Profile of Diuretics in Treatment of Hypertension
}

\author{
Ashgan Abo Elmaaty Abd Ellatif \\ Department of Medicine, Faculty of Medicine, Mansoura University
}

\begin{abstract}
It is well established that Diuretics have been the keystone of antihypertensive therapy where decreasing mortality, morbidity and related cardiovascular disease, so the aim of our present study was to investigate the non acceptable side effects of diuretics as anti-hypertensive therapy. More than 10 years of my medical practical life I find that after few months from the start of treatment with diuretics systolic blood pressure decreases to some how normal range for example 130,135, and 140, while diastolic blood pressure decreases to some how high range, for example 90, 95, and 100. This observation increases during summer which is the season of losing body water by sweeting.
\end{abstract}

Keywords: hypertension, diuretics, complication

\section{INTRODUCTION}

In 1937, the treatment of hypertension by using of diuretics was considered the first line of therapy either alone or in combination with other therapeutic drugs ${ }^{1}$.Several studies demonstrated the effect of diuretics in reducing mortality and morbidity of stroke ${ }^{2}$. Thiazide diuretic is very effective in preventing the development of heart failure (HF) in hypertensive patients. In a large meta-analysis that included 18 long-term placebo controlled randomized trials high-dose diuretic therapy reduced the risk of HF by $83 \%$ and low-dose diuretic reduced the risk of HF by $42 \%{ }^{3}$. Thereare two old drugs that are still useful, hydrochlorothiazide and chlorthalidone, the first drug used more in United States and the second used more in United Kingdom, ${ }^{4,5}$.

\section{Complications of DiURetics}

There are many adverse effects of thiazide diuretics as hypokalemia and changes in lipid profile $^{6}$.Hypokalemia suppresses pancreatic insulin release and thus predisposes to hyperglycemia and worsening of existent Diabetes Mellitus ${ }^{7}$. Diuretics can cause decrease of blood volume with orthostatic hypotension or even cardiovascular collapse. The reduction in renal blood flow secondary to volume depletion can produce oliguria and azotemia ${ }^{8}$.

In one study, hyponatremia occurred in $17 \%$ of patients ${ }^{2}$. The risk of hyponatremia appears to be particularly common in elderly female patients ${ }^{1}$. Hyponatremia can lead to confusion, delerium and irreversible brain damage that may contribute to age-related dementia ${ }^{2}$. The utilization of low to medium doses of diuretics, along with issuing patient instructions to limit fluid intake may help minimize this risk ${ }^{1}$.

No studies delt with the complication of systolic-diastolic blood pressure ratio, so the aim of the present study is to discover new side effect of diuretics in treating hypertensive patients.

\section{Patients And Methods}

Healthy and patient groups were described as 50 healthy men (G1) aged from $46-57$ years with blood pressure ranged from 120-123 systolic blood pressure and from 80-82 diastolic blood pressure, while patient group consists of203Patients treated with antihypertensive drugs + diuretic (G2) and (203) Patients treated with antihypertensive drugs without diuretics.

\section{ReSUlts}

The results of Systolic blood pressure was highly significant $(\mathrm{P} \leq 0.05)$ decrease as evidenced by measuring blood pressure $(120.82 \pm 1.26)$ when compared with Patients treated with antihypertensive drugs + diuretic (132.24 \pm 2.18 ) (table1) and (fig.1). In case of diastolic blood pressure was highly 
significant $(\mathrm{P} \leq 0.05)$ increase $(92.07 \pm 2.1)$ in Patients treated with antihypertensive drugs + diuretic when compared with Patients treated with antihypertensive drugs only $(79.94 \pm 1.4),($ table1) and (fig.1).

Table1. Blood pressure ( $\mathrm{mmHg}$ ) in control (50), patients treated with antihypertensive drugs with diuretic drug (203) and patients treated with antihypertensive drugs without diuretic drug (203)

\begin{tabular}{|c|c|c|}
\hline Groups & $\begin{array}{c}\text { Systolic blood pressure } \\
(\mathrm{mmHg})\end{array}$ & $\begin{array}{c}\text { Diastolic blood pressure } \\
(\mathrm{mmHg})\end{array}$ \\
\hline Control (50) & 116.2 & 75.24 \\
& $\pm 3.52^{\mathrm{a}}$ & $92.48^{\mathrm{a}}$ \\
\hline Patients treated with antihypertensive drugs & 132.24 & $\pm 2.1^{\mathrm{b}}$ \\
\hline diuretic (203) & $\pm 2.18^{\mathrm{b}}$ & 79.94 \\
\hline Patients treated with antihypertensive drugs & 120.82 & $\pm 1.4^{\mathrm{c}}$ \\
\hline
\end{tabular}

Each value represent the mean $\pm S D$, values superscripts with different letters $(a-c)$ were significantly different at $p \leq 0.05$.
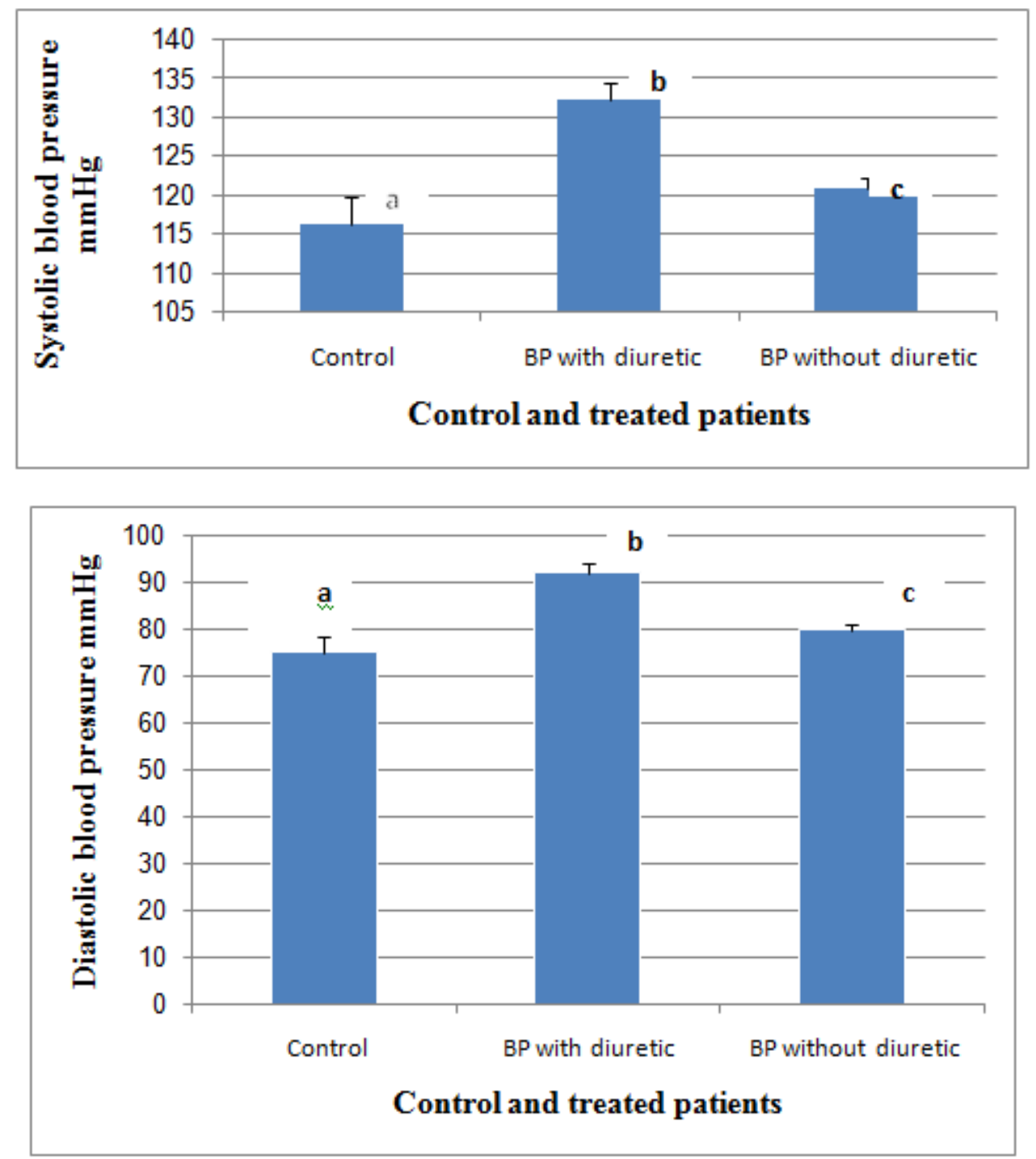

\section{OVERVIEW OF CASE REPORT STUDY}

There was one nice case worked at Mansoura college of medicine, he was suffering really from an abscess in his teeth for more than 7 days. The dentist refused to remove his suffering tooth because his blood pressure never change 130/95. Of course, he was treated by diuretic and also concore. He came to our consultant and I sayed stop diuretic at once. The next day he did not come to me. I met him the following day with his tooth removed, with his suffer stopped and with his blood pressure 125/80. Like this case I met hundreds and hundreds and they all respond to the same advice, "Stop diuretic at once". 


\section{DISCUSSION}

Hypertension is considered one of the most important preventable contributors to disease and death. Antihypertensive drug treatment is one of the most important health outcomes in reducing hypertension ${ }^{9}$.Many studies showed that diuretics decrease the incidance of osteoporosis and lower the risk of hip fractures ${ }^{10}$. Several studies revealed that use of diuretic like thiazide increased level of glucose $^{11}$. Grossman et al. in $1999^{12}$, used diuretic as a long term where showed an increased risk of renal cell carcinoma. In other studies, diuretics increased triglyceride and cholesterol levels, by increase in LDL cholesterol ${ }^{13}$. There are no studies revealing the side effect of diuretics related to systolic and diastolic blood pressure relationship. So, from our present study we discussed that a diuretic causes decrease of body water and so blood volume decreases gradually till an effective degree of loss. This means decrease of blood volume rationable to this amount of body water loss. The volume of blood pumped by the heart decreases, hat is the systolic blood pressure decreases. The blood vessel in which the volume of blood decreased constricts to accommodate to this decreased volume of blood within it and the result will be increased peripheral resistance that is increase diastolic blood pressure, (as an example blood pressure 132/90). At this case the patient comes disturbed and complaining of headache and instability because of his high diastolic pressure. The doctor hurries to add vasodilator as ACE inhibitors for example. It takes a period of time for the constricted vessel to dilate and remain dilated, because for the vessel to remain dilated it must be filled with the sufficient amount of blood necessary to keep it maintained dilated, meanwhile the doctor is still giving his patient the diuretic which still decreases the blood volume, so it takes time and stills the case within stability and instability as long as a diuretic is still used. As regards me, once the patient comes in this case, taking a diuretic and with blood pressure 130,135, and 140 over 90, 95, and 100 and having headache and instability, I stop diuretic at once. The patient comes after one or two days at maximum with a reasonable blood pressure of reasonable ratio between systolic and diastolic blood pressure for example 122/80 because blood volume starts to increase and returns to its normal value, so the blood vessel starts to dilate by the increased volume of blood and so the peripheral resistance decreases and the diastolic blood pressure decreases to return to its reasonable value. The pumped stroke volume meets that lowered peripheral resistance, the systolic blood pressure also becomes lowered, as an example patient with blood pressure 135/90 becomes now $122 / 80$ after stop diuretic.

\section{CONCLUSION AND RECOMMENDATION}

From our present study, we concluded that, it is not logic, not natural and not safe to dry the living being from its water which is the cause and fellow of life, flourish and fertility. It is the medium and mediator for all life reactions, specially the hypertensive patient is mostly advancing in age and his body is going on losing water by nature then how I come as a physicion to increase this very harmful loss of water. I recommend to restrict using diuretic only after adjusting blood pressure as possible as we can with vasodilator (ACE inhibitor) as an example and yet the systolic still resists adjustment and still higher than we need. In this case only we introduce by small dose of diuretic till increased blood pressure is adjusted completely. We must go by treatment directly to the home of trouble, that is the blood vessel itself, by graduating dose of vasodilator and restrict use of diuretic to cases mentioned before. Personally I discovered so many cases by this important notice to the extent that I named it joking "Ashgan' low" as follows: reasonable high systolic blood pressure (for example 130,135,140 ) over irrationable high diastolic blood pressure ( for example 90,95,100 $)=$ low blood volume $=$ chronic loss of body water. There are two very important causes of chronic loss of water, first Diabetes Mellitus and second Chronic Renal Failure. Once I discovered my patient with irrationable high diastolic blood pressure I direct ahead to first stop diuretic at once, adjust blood pressure by vasodilator and lastly investigate for Diabetes Mellitus and renal trouble. So many cases and cases I discovered by this simple observation "The joking Ashgan' low ". I introduce my humble work to all my dear colleagues and all our kind patients.

\section{ACKNOWLEDGEMENT}

Author would to thank to Dr. Reda Eldemerdash, Urology and Nephrology Center, Mansoura University, Mansoura, Egypt for his effort with me in writting this paper. 


\section{REFERENCES}

[1] Chobanian AV, Bakris GL, Black HR, et al. The Seventh Report of the Joint National Committee on Prevention, Detection, Evaluation, and Treatment of High Blood Pressure: the JNC 7 report. JAMA; 289:2560-2572.2003.

[2] MRC Working Party. Medical Research Council trial of treatment of hypertension in older adults: principal results. BMJ; 304:405-412.1992.

[3] Psaty BM, Smith NL, Siscovick DS.et al. Health outcomes associated with antihypertensive therapies used as first-line agents: a systematic review and meta-analysis. JAMA.; 277:739$745,1997$.

[4] ALLHAT Officers and Coordinators for the ALLHAT Collaborative Research Group; The Antihypertensive and Lipid-Lowering Treatment to Prevent Heart Attack Trial. Major outcomes in high-risk hypertensive patients randomized to angiotensin-converting enzyme inhibitor or calcium channel blocker vs diuretic: the Antihypertensive and Lipid- Lowering Treatment to Prevent Heart Attack Trial (ALLHAT). JAMA; 288:2981-2997, 2002.

[5] McCormack T, Krause T, O'Flynn N. Management of hypertension in adults in primary care: NICE guideline. Br J Gen Pract; 62:163-164, 2012.

[6] Thiazide diuretic induced hyperlipidemia. (drug consult) Micromedex inc. Vol.95.

[7] Wolff FW, Parmley WW, White K, Okun R. Drug-induced diabetes. Diabetogenic activity of long-term administration of benzothiadiazines. JAMA; 185:102-108, 1963.

[8] Morgan T. The use of diuretic drugs and aldosterone antagonists in hypertension. In: Doyle AE, ed. Handbook of Hypertension, vol 5. Amsterdam: Elsevier,: 67-91,1984.

[9] Beckett NS, Peters R, Fletcher AE, et al; HYVET Study Group. Treatment of hypertension in patients80 years of age or older. N Engl J Med.; 358 (18):1887-1898, 2008.

[10] Bolland MJ, Ames RW, Horne AM, Orr- Walker BJ, Gamble GD, Reid IR. The effect of treatment with a thiazide diuretic for 4 years on bone density in normal postmenopausal women. Osteoporos Int; 18:479-486, 2007.

[11] Dahl öf B, Sever PS, Poulter NR, et al. Prevention of cardiovascular events with an antihypertensive regimen of amlodipine adding perindopril as required versusatenolol adding bendroflumethiazideas required, in the Anglo-Scandinavian Cardiac Outcomes Trial-Blood Pressure Lowering Arm (ASCOT-BPLA): a multicenter randomised controlled trial. Lancet; 366:895-906, 2005.

[12] Grossman E, Messerli FH, Goldbourt U. Does diuretic therapy increase the risk ofrenal cell carcinoma? Am J Cardiol; 83:1090-1093, 1999.

[13] Kasiske BL, Ma JZ, Kalil RS, Louis TA. Effects of antihypertensive therapy on serumlipids. Ann Intern Med; 122:133-141, 1995. 